by his lead and his enthusiasm for the subject.

I find little in this book to take issue with. The treatment follows the twentieth century continental European approach, and will therefore be accessible to cartographers on both sides of the Atlantic. The numerous illustrations are clear and consistently presented. Indeed, this is the most comprehensive collection of diagrams of the projections used in world mapping and is even more complete than the splendid Album of Map Projections (by Snyder and P. M. Voxland) published by the US Geological Survey in 1989.

One limitation is that the applications are largely confined to European and North American literature. Apart from the Arab contribution, other cultures seem to have been ignored. For example, there is no mention of the early Chinese work unearthed by Joseph Needham, and published in Volume 3 of his monumental Science and Civilisation in China (1959), where he described the use in AD 940 of the Tunhuang star chart which represents the independent discovery of Mercator's projection by Ch'ien Lo Chih more than 500 years earlier.

D. H. Maling is at Tredustan Hall, Defynnog, Brecon, Powys LD3 8YH, UK.

\title{
Dawning of agriculture
}

\section{Jared M. Diamond}

\section{Domestication of Plants in the Old World.} Second Edition. By Daniel Zohary and Maria Hopf. Oxford University Press (Clarendon Press): 1993. Pp. 278. £35, $\$ 52.50$.

THIS book is of much wider significance than its title suggests, as plant and animal domestication is important to two diverse groups of scientists. For evolutionary biologists, changes under artificial selection yield clear insights into evolutionary processes. Hence Darwin devoted the first chapter of his Origin of Species to variation under domestication. For students of human society, domestication launched the chain of developments leading to complex societies and thus to writing, metallurgy and empires. Geographical differences in domestication probably contributed to the widely differing trajectories and rates of development of societies in different parts of the world.

Among the world's centres of domestication, the one in which plant domestication is best understood is Southwest Asia (alias the Near East). That is fortunate, because Southwest Asia may be the earliest centre of domestication, as well as of writing and other marks of civilization. For most crops of Southwest Asian origin, the ancestral wild species has been identified by comparative morphology and genetics, and the ancestor's wild distribution and ecology are known. For many of these crops, the time and place of domestication can be pinpointed by plant remains from hundreds of carbon-dated archaeological sites spanning the past 12,000 years. The outcomes of crosses of the crop with its wild progenitor and with related wild species have been studied, and chromosomal, genetic, morphological and physiological changes that occurred under domestication have been identified.

The summarizing of this information in the first edition of Zohary's and Hopf's book in 1988 made it the outstanding account of plant domestication for any area of the world. The second edition incorporates the accelerating advances of the past five years. In the accounts of vegetables, fruit and nut trees and dye crops, the added information makes this revision virtually a new book. Much new detail has also been added to the treatments of cereals, legumes, oil crops, fibres, condiments and wild-collected fruits.

The book is organized into two main sections. First, for each of 78 crops or plants, grouped in the above-mentioned categories, the wild relatives, archaeological finds and evolutionary changes are summarized. The second section summarizes plant remains from 150 selected archaeological sites spanning the Old World from India west to Britain, and from Egypt north to Finland. A brief final chapter provides some general conclusions.

This book is indeed a 'mine of information'. An enormous and diverse body of important results is digested and presented economically, in a form that should encourage other authors to mine it and apply the results to their own fields. Just three examples must suffice.

First, the map on pages 232-233 uses a compact set of symbols to depict dates for the centrifugal spread of six early crops from Southwest Asia west across Europe and east to India. Details of this map will surely also be scrutinized by linguists concerned with the spread of IndoEuropean languages, and by population biologists concerned with the genetic origins of modern Europeans.

Second, the same 'package' of eight or nine crops that founded agriculture in Southwest Asia founded it later in Europe, Egypt and the Indus Valley. Evidently, these so-called founder crops and the founder domesticated animals associated with them constituted a powerful economic package that diffused rapidly along Eurasia's East-West axis. The founders' spread pre-empted independent domestications of the same crops outside Southwest Asia, as well as pre-empting domestication of other potentially domesticatable related species within Southwest Asia. Identification of chromosomal types and of mutant changes under domestication shows that, for most of the founder crops, all extant varieties are descended from a single domestication event. In contrast, spread of crops along the New World's North-South axis was much slower, with the result that the same species or related species were repeatedly domesticated independently in South America, Meso-America and eastern North America.

Third, the main sequence of plant domestication in Southwest Asia began with predominantly self-pollinated but occasionally cross-pollinated annuals (the founder cereals and legumes), proceeded through vegetatively propagated fruit trees, and led to fruit trees requiring mastery of difficult grafting techniques. In parallel with, or late in, this sequence came the evolution of weeds infesting fields of these primary crops; the weeds became crops in their own right, as in the case of oats and, probably, lettuce. These sequences fit well with evolutionary perspectives that view plant domestication as an initially unintended outcome of human harvesting of wild plants. The relationship between unconscious selection by humans and the resulting diverse changes under domestication is often transparent. For example, wild-pea pods, which disperse their peas by popping open, evolved by a single recessive mutation into domesticated peas with pods that do not pop open, because peas from popped pods would be lost and could not be gathered by human harvesters.

For anyone concerned with Old World plant domestication, this book in its revised edition will become the main reference. It will also be essential reading for many scientists who have no direct interest in the Old World or in plant domestication, but whose subject matter grows out of those subjects. That includes especially historians, cultural anthropologists, archaeologists, linguists, evolutionary biologists and students of human genetics and diseases. For botanists and agronomists concerned with plant domestication elsewhere in the world, Zohary and Hopf's synthesis for western Eurasia will serve as the standard at which to aim, and as a basis for intercontinental comparisons.

Jared M. Diamond is in the Department of Physiology, University of California Medical School, Los Angeles, California 900241751, USA. 